\title{
A memória em questão: uma perspectiva histórico-cultural *
}

\author{
Ana Luiza Bustamante Smolka**
}

RESUMO: Este texto tematiza a memória enquanto prática social, enfocando os muitos modos, historicamente constituídos, de pensar e de falar sobre memória. Procura compreender os modos de elaboração coletiva da memória, buscando indícios da constituição da memória no nível individual e indagando sobre a dimensão discursiva, sobre o estatuto da linguagem nessa constituição.

Palavras-chave: Memória, memória e práticas sociais, linguagem e memória

\section{Introdução}

As pesquisas mais recentes sobre memória têm feito referência a trabalhos do final do século passado, considerados fundadores, como os de Bergson, na filosofia; de Freud, na psicanálise; de Proust, na literatura; de Ebbinghaus, na psicologia; a partir dos quais se desdobraram, no início desse século, investigações em várias áreas do conhecimento. Nessas diversas áreas, e dentre elas, sem dúvida, na psicologia, as pes-

\footnotetext{
* Este trabalho contou com o apoio do CNPq, referente ao Projeto Integrado de Pesquisa intitulado "Práticas Sociais, Processos de Significação e Educação Prospectiva". A parte aqui apresentada refere-se ao subprojeto "Memória e História na Escola". Versões da parte empírica da pesquisa foram apresentadas na ANPED/98 e no IV Congress of the International Society for Cultural Research and Activity Theory, Aarhus, Dinamarca, 1998.
}

** Professora da Faculdade de Educação, Unicamp. E-mail: smolka@obelix.unicamp.br 
quisas têm procurado circunscrever e definir o mais claramente possível os contornos conceituais do que seja memória. Ao longo do século XX, assistimos a inúmeros debates sobre o assunto, configurando as mais variadas tendências e perspectivas.

O que é a memória e como ela pode ser estudada? É uma provocativa pergunta formulada por Edwards, Potter \& Middleton (1992) para iniciar um texto no qual eles argumentam a favor de uma psicologia discursiva da rememoração, opondo-se à tendência que representa uma parte significativa dos esforços na psicologia atual. Questionando a relevância de uma memória "abstraída" e contestando os modos como a psicologia tem se proposto a investigar a "faculdade cognitiva da memória", eles indagam sobre como abordar essa "faculdade" e o que é possível dizer sobre ela. "Sem dúvida a linguagem tem proporcionado a base mais penetrante para operacionalizar e teorizar sobre a memória... Todos os estudos de memória são estudos de desempenho, operacionalizados por medidas de capacidades... Inserindo o estudo da memória dentro do estudo do discurso muitas preocupações teóricas dos psicólogos podem ser redefinidas..." (Edwards, Potter \& Middleton 1992, p. 441).

A pergunta inicial dos autores, que sem dúvida não é nova, se insere numa instigante polêmica que abrange questões epistemológicas importantes como as relações entre experiência e conhecimento, linguagem e funcionamento mental, cognição e memória, dentre muitas outras. Ao destacar e sugerir uma definição de memória, a pergunta, tal como formulada, indica um certo modo de pensar e uma certa esfera de preocupações que apontam para opções teóricas, restrições e, também, esquecimentos.

Em se falando de esquecimentos, vale lembrar que os trabalhos de Edwards, Potter e Middleton fazem referência ao erudito e já clássico estudo de Frances Yates, The Art of Memory, publicado em 1966. E é interessante apontar que não encontramos, em nenhum outro texto consultado na área da psicologia, referência ao trabalho de Yates. No âmbito da psicologia, portanto, eles parecem ser dos poucos (os únicos?) a mencionarem esse estudo, que talvez seja considerado e lembrado como pertencendo à área da história ou da filosofia.

Ousamos, no presente trabalho, fazer uma incursão por vários textos, incluindo alguns referentes à antiga Grécia, com o objetivo de procurar compreender os muitos modos, historicamente construídos, de pensar e de falar sobre memória. Modos que herdamos sem saber, sem necessariamente nos darmos conta. Modos que se inscrevem nos nos- 
sos modos contemporâneos de pensar, de falar, de lembrar, de investigar hoje. Modos estabilizados, muitas vezes "esquecidos".

Pensar e estudar sobre a "formação da mente" em um perspectiva histórico-cultural implica compreender e relevar esses aspectos. Não estamos preocupados com uma cronologia das idéias sobre memória. Procuramos entender as condições, os modos de produção e as práticas que envolvem motivos e formas de lembrar e esquecer, maneiras de contar, de fazer e registrar histórias.

Há alguns anos, a nossa proposta de trabalho de investigação vem focalizando a educação e o discurso como práticas fundamentais na constituição do psiquismo humano e tem se realizado na interseção de várias áreas do conhecimento (Psicologia, Filosofia, Educação, História, Estudos da Linguagem...). Nosso interesse pelas Musas e nossa busca por The Art of Memory encontram-se, desse modo, justificados. O que pode parecer um descaminho, um devaneio, naquilo que concerne mais especificamente a uma psicologia do desenvolvimento humano, encontra sua razão de ser nos próprios fundamentos da perspectiva teórica assumida e nos objetivos do trabalho em questão.

\title{
Dos muitos modos de pensar e de falar sobre memória
}

\author{
Um pouco do que herdamos
}

A memória em questão São muitos os modos de pensar e de falar sobre memória. Memória faculdade, função, atividade; memória local, arquivo; memória acúmulo, estocagem, armazenagem; memória ordem, organização, memória técnica, techné, arte; memória duração... memória ritmo, vestígio; memória marca, registro; memória documento, história... Memória como aprendizagem - processo, processamento; memória como narração - linguagem, texto. Memória como instituição... Invenção da memória. 
Mnemosyne, deusa, Memória divinizada, gera nove Musas, as Palavras Cantadas. E "as Musas colocaram então na mão do poeta o bastão de seu ofício e insuflaram nele sua inspiração..." Inspirado pela Musa, o aedo cria, repete, recita, compõe palavras em ritmos. Inspirado pela Musa, o poeta é suporte e mestre da verdade. Resgata o acontecido do esquecimento, presentifica o passado. Versejar é lembrar. Cantar é lembrar.

Enquanto filhas da Memória, as Musas detém um poder numinoso cuja força, ao mesmo tempo, presentifica e encobre. Elas fazem revelações, alethéa, mas impõem, também, o esquecimento, léthe. É na voz das Musas, pelas palavras, na linguagem, que se dá a nomeação, a presentificação, a revelação, e também o simulacro, a mentira, o esquecimento. Ulisses chora ao ouvir o canto do aedo sobre o que havia protagonizado. Chora ao escutar a história de sua própria vida (o acontecido, a verdade). E consegue resistir ao canto das sereias (o esquecimento, a perdição, a morte).

Na palavra cantada, o poder da palavra. Inspiração. Emoção. Sedução. Mímesis: o impacto, o efeito, a ação, a força da palavra do outro, levam a imitar, a repetir, a reter, a memorizar (canto do poeta, do aedo). Mas podem também levar a esquecer (o retorno), a perder-se (canto da sereia).

A poesia do poeta homérico, versão - autorizada - da palavra pública, tem, por isso mesmo, um poder de sustentar, de controlar, de certa forma, a cultura, a tradição. Mas se a tradição deve ser praticada e permanecer estável, precisa ser lembrada por todos. Precisa corresponder às possibilidades de memorização das pessoas comuns, e não apenas das mais bem dotadas. Na memória ritmica, então, a maneira mais direta de imitação, de memorização, de sustentação da tradição. A Musa, voz da instrução, é também a voz do prazer. A memória toda de um povo é poetizada.

Prática da memória na palavra (en)cantada, na poesia. Poesia como comunicação conservada. Toda memorização da tradição poetizada depende da recitação constante e reiterada. Não há como reportar-se à escrita para lembrar... (Havelock, Torrano, Le Goff, Detienne, Menezes, Gagnebin) 
II.

Prática da memória nos exercícios para aprender (a exemplo dos pitagóricos), prática da memória no exercício da palavra em público, na oratória; prática da memória como retórica, como palavra sedutora, persuasiva, convincente. Importância e necessidade de exercitar a memória: além da reminiscência, o esforço da recordação. Memória não tanto, ou não só, como deusa. Dessacralização da memória. Memória não apenas como tradição. Memória como techné, Mnemotécnica. Arte da memória.

Simonides de Céos, poeta e pintor no século $V$ a.C., parece ter sido o primeiro a estabelecer os princípios, ou a definir as regras dessa arte. A recordação mnemônica requer 1. a lembrança e a criação de imagens na memória; 2. a organização das imagens em locais, ou lugares da memória. Como poeta e pintor, Simônides trabalha articuladamente os métodos da poesia e da pintura: pintura é poesia silenciosa; poesia é pintura que fala. Tanto para a poesia como para a pintura, e também para a arte da memória, é dada importância excepcional à visualização intensa. É preciso ver locais, ver imagens.

Podemos imaginar que formas dessa arte, eram, de fato, utilizadas pelos bardos e contadores de histórias na Antiguidade. O que Simônides introduz ou formaliza como prática é indicativo, no entanto, de certas mudanças nas formas de produção e organização social, de base exclusivamente oral, em transição para a escrita. Mudanças que transformam a posição do poeta na sociedade.

A partir dos princípios e regras ensinados e publicados por Simônides, desdobra-se, apura-se com os gregos e os romanos, a mnemotécnica: Ad Herenium, livro compilado por um professor anônimo de retórica; De oratore, de Cícero; Institutio oratoria, de Quintiliano; formalizam os princípios, propõem e detalham os métodos. Em seu maravilhoso livro, The Art of Memory, Frances Yates comenta sobre essa Arte, dando-nos a conhecer sobre esses princípios e métodos.

Vamos agora, considerar a valiosa casa de invenções, a guardadora de todas as partes da retórica, a memória... Há dois tipos de memória, uma natural, outra artificial. A memória natural é gravada em nossas mentes, nasce simultaneamente com o pensamento. A memória artificial é a memória fortalecida ou confirma- 
da pelo treino. Uma boa memória natural, e também uma fraca, podem ser melhoradas pela arte (thecné).

Agora, eu vou falar da memória artificial... A memória artificial é estabelecida a partir de locais e imagens, a definição do guardado para ser repetido pelos tempos. Um local é um lugar facilmente apreendido pela memória, como uma casa, um espaço entre colunas, um canto, um arco, etc. Imagens e formas, marcas e simulacros (formae, notate, simulacra) daquilo que queremos lembrar. Por exemplo, se queremos lembrar o gênio de um cavalo, de um leão, de uma águia, devemos colocar suas imagens em determinados lugares.

A arte de memória é como uma escrita interna... os locais são como tábuas de cera ou papirus, as imagens como letras, o arranjo e a disposição de imagens, como o script, e a fala, a recitação, como a leitura... Os lugares permanecem na memória e podem ser usados novamente, muitas vezes...

Bastante já foi dito de lugares. Agora vamos para a teoria das imagens. ... há dois tipos de imagens, uma para coisas (res), e uma para palavras (verba). Isto quer dizer, memória para coisas forma imagens para lembrar de um argumento, noção, ou uma coisa; mas memória para palavras tem que achar imagens para lembrar de cada palavra. (Ad Herenium, apud Yates, pp. 5-8)

O estudante que deseja adquirir memória para palavras começa do mesmo modo que o estudante da memória para coisas; isto é, ele memoriza lugares para sustentar suas imagens. Mas ele é confrontado com uma tarefa muito mais árdua porque muitos mais lugares serão necessários para memorizar todas as palavras de uma fala do que seriam para suas noções. O tipo de imagens para memória de palavras são do mesmo tipo que as da memória para coisas, ou seja, elas representam figuras humanas de um caráter espantoso e não usual e em situações dramáticas surpreendentes - imagines agentes (Yates 1966, p. 13).

Devemos, então, dispor imagens de maneira que possam aderir mais longamente à memória. E devemos fazer isso se estabelecermos semelhanças as mais notáveis possíveis; se fixarmos imagens que não sejam nem muitas nem vagas, mas ativas (imagines agentes); se atribuirmos a elas beleza excepcional ou feiura sin- 
gular; se ornarmos algumas delas com coroas ou capas, de modo que a similitude possa ser ressaltada para nós; ou se de algum modo as desfigurarmos, introduzindo uma mancha de sangue, ou sujarmos com lama, ou tinta, de maneira que sua forma fique mais admirável; ou atribuindo ainda certos efeitos cômicos às imagens, porque isso também assegura nossa recordação mais rápida. ( $A d$ Herenium, apud Yates, pp. 9-10)

Yates vai comentar sobre a intensa ginástica interna, sobre esse trabalho invisível que pode nos parecer tão estranho, mas que, ao mesmo tempo, nos indica formas de organização, da arquitetura, de prática da memória antiga.

A memória para palavras, que é essencial para nós, tem distinção por uma maior variedade de imagens (em contraste com o uso da imagem de uma palavra por uma sentença da qual ele vem falando); porque há muitas palavras que servem para conectar partes de uma sentença, e estas não podem ser formadas por similitude - dessas que temos que modelar imagens para emprego constante; mas a memória para coisas é a propriedade especial do orador -esta podemos imprimir nas nossas mentes por um arranjo habilidoso de várias máscaras (singulis personis) que as representam, de modo que podemos apreender idéias por meio de imagens e a sua ordem por meio de locais. (Ad Henrenium, apud Yates 1966, p. 18)

Um método para lembrar envolve, portanto, disciplina e arte. Figuras humanas, ativas e dramáticas, extremamente belas ou exageradamente grotescas, representam coisas, e atuam e narram, são poderosos agentes mentais. Essas imagines agentes, essas singulis personis, vão repercutir fortemente na Idade Média, sobretudo através dos trabalhos de Cícero e de Quintiliano, retomados e interpretados pelos escolásticos.

\section{III.}

Por volta dos séc. V e IV a.C., Platão encontra-se em meio a uma instigante arena de luta. São séculos de exercitação da experiência rítmica memorizada, conservada em formas de enunciados verbais, na 
memória viva das pessoas, como modo de consciência partilhado, como tradição. Os nomoi (normas, leis) e os ethe (práticas, hábitos, costumes, sentimentos e reações particulares) persistem como estado mental oral do povo. Mas o conhecimento e as habilidades de escrita vão sendo gradativa e penosamente difundidos, na tensão entre o restrito acesso e insipientes condições, e o lento movimento de expansão da alfabetização e a universalização das letras.

Simultaneamente, nesse mesmo período, vai se transformando e difundindo o conceito de psyche, como "espírito que pensa" (Havelock p. 213), elaboração atribuída inicialmente a Sócrates.

Em seu "Prefácio a Platão", Havelock analisa a emergência dessa "personalidade", desse "eu" pensante, que se distingue e se destaca, que se autogoverna.

A psyche que lentamente se afirma como independente da atuação poética e da tradição poetizada precisava ser uma psique reflexiva, ponderada, crítica, ou não poderia ser nada. Juntamente com a descoberta da alma, a Grécia, à época de Platão e imediatamente antes dele, precisava descobrir algo mais -a atividade do puro pensamento. Os eruditos já chamaram atenção, nesse período, para transformações que estavam ocorrendo no significado de palavras denotadoras de vários tipos de atividade mental. (Havelock 1996, p. 216)

À afirmação da psicologia do indivíduo autônomo vai corresponder a rejeição dos poetas. Quanto mais se afirma a prevalência de uma personalidade racional autônoma e a necessidade ou a supremacia dos processos de reflexão, mais difícil se torna aceitar a mímesis.

Platão suspeita da mímesis, critica a poesia - não pela criação, mas pela sedução: a atração da mímesis é estranha ao "pensar". O filósofo, amante da verdade e da sabedoria, difere do poeta, amante de espetáculos e da opinião. Com Platão, uma teoria da Memória é fundamentalmente uma teoria do Conhecimento.

No Teeteto, Platão usa a metáfora de um bloco de cera para falar da memória - há um bloco de cera em nossas almas. É presente de Mnemosine, mãe das Musas. Em cada indivíduo o bloco de cera tem qualidades diferentes. A cera não é nem tão flúida quanto a água, que não 
permite reter, nem tão dura quanto o ferro, que não permite marcar. Guarda impressões por excelência.

Mas para Platão, há um conhecimento que não é derivado das impressões sensoriais. Estão latentes em nossas memórias as Formas das Idéias, Formas de realidades que a alma conheceu antes de cada um nascer. O verdadeiro conhecimento consiste em ajustar as marcas das impressões sensoriais à forma da realidade superior, da qual as coisas são meros reflexos. Todos os objetos sensíveis têm referência em certos (arque)tipos aos quais se assemelham. Nós não vimos ou aprendemos esses arquetipos nessa vida. O conhecimento deles é inato em nossa memória. Assim, por exemplo, a idéia de igualdade é inata.

No Fedro, a verdadeira função da retórica é falar a verdade e persuadir os homens do conhecimento da verdade. O Fedro é um tratado sobre a retórica, no qual a retórica é olhada não como arte de persuasão para ser usada para vantagens individuais ou políticas, mas como uma arte de falar a verdade e persuadir os ouvintes para a verdade. $O$ poder para fazer isto depende do conhecimento da alma e o conhecimento verdadeiro da alma consiste na lembrança das Idéias.

No Fedon, Platão expõe claramente a teoria das Idéias. O conhecimento da verdade e da alma consiste na recordação. Como a lógica platônica opera por modelos, aprender é recordar, re-conhecer. Memória é conhecimento da Verdade. Toda aprendizagem e todo conhecimento são uma tentativa de relembrar as realidades, as essências. Desse modo, a memória em Platão não é organizada nos termos (triviais?) da mnemotécnica, mas concebida em relação às realidades. Não é uma parte da arte da retórica. No sentido platônico, a memória - como re-conhecimento - é o trabalho fundante do todo.

Diante da Razão, forma de pensar emergente, o que é a Mímesis senão sombra da sombra, cópia da cópia, aparência da aparência?! O pintor e o poeta são incapazes de fazer cópias das Formas. Há insensatez no poeta possuído pelas Musas... Com Platão, a memória perde o aspecto mítico.

Mas se Platão se opõe à experiência poética homérica, à função mais arcaica (que envolve a noção de arché, princípio inaugural) da Memória, às Palavras Cantadas, inspiradas pelas Musas, ele também se opõe à escrita, veneno que oblitera a memória.

Desse modo, podemos esquematizar: 


\author{
Episteme - Logos \\ conhecimento da verdade \\ realidade racional
}

lógica

Mnemotécnica

Arte da memória

Mnemo - techné

(fazer sujeito a regras)

palavra oral - viva

faz lembrar

memória viva

dentro, processo interior x Mímesis

mascara a verdade, veicula idéias falsas

veneno psíquico, alimenta paixões

poesia, palavra cantada

$x \quad$ Escrita

Morte da memória

só pode (se) repetir

palavra fixa, significa sempre o mesmo

faz esquecer

memória auxiliar

fora, exterior à memória

O Fedro aborda essa questão fundamental: reminiscência da essência x lembrança pela escrita. Para Platão, há uma incompatibilidade entre o que está escrito e o que é verdadeiro: É decente ou indecente escrever? O que é escrever de um belo modo? (274b). A escrita é simulacro e sedução.

De fato, no Fedro, Sócrates encontra-se seduzido:

Fedro: ... tu fazes crer que é um estrangeiro que se deixa conduzir, e não um natural deste lugar. Fato é que não deixas a cidade nem para viajar além das fronteiras...

Sócrates: ... veja, gosto de aprender. Assim, o campo e as árvores nada me ensinam, mas sim, os homens da cidade. Tu, contudo, pareces ter descoberto a droga para me fazer sair!... Assim tu fazes para mim: com discursos em folhas que seguras diante de mim, facilmente me farás circular através de toda a Ática, e ainda além, onde bem quiseres! ... faça tua leitura. (230 d,e) 
Como Derrida comenta,

Um discurso presentemente proferido em presença de Sócrates não teria tido o mesmo efeito. Apenas os lógoi in biblíois, falas diferidas, reservadas, envolvidas, enroladas, fazendo-se aguardar em espécie e ao abrigo de um objeto sólido, deixando-se desejar o tempo de um caminho, apenas as letras ocultadas podem fazer Sócrates caminhar desta forma. (1991, p.15)

A sedução, o desvio, o descaminho, então, não mais pela palavra cantada. Agora, o lógoi in biblíois, um outro modo de falar, uma outra forma de discurso, um outro modo de lembrar: a escrita - Pharmakon remédio e veneno.

Não é para a memória, é para a rememoração que descobriste o remédio (Fedro, 275a)

As resistênicas e a desconfiança de Platão com relação à escrita remetem, portanto, aos deslocamentos e às transformações que a difusão do texto escrito provocava na cultura, nos modos de vida e de conhecimento das pessoas: democratização, dessacralização, banalização, perversão da atividade de lembrar. (Gagnebin, 1997, p. 53). Laicização da memória, criação e investimento em novas técnicas, novas possibilidades.

\section{IV.}

Aristóteles distingue a memória propriamente dita, a mneme, faculdade de conservar o passado; da reminiscência, a mamnesi, faculdade de invocar voluntariamente o passado. Sua teoria do conhecimento traz novas contribuições ao estudo da memória.

Para Aristóteles, as impressões sensoriais são a fonte básica de conhecimento; sem elas, não pode haver conhecimento. As percepções trazidas pelos sentidos são primeiramente tratadas pela faculdade da imaginação e são as imagens assim formadas que tornam-se material para a faculdade intelectual. A imaginação é vista como intermediário entre a percepção e o pensamento. É essa parte da alma, responsável por produzir imagens, que possibilita os processos superiores de pen- 
samento. A alma nunca pensa sem uma 'imagem mental'; a faculdade de pensar pensa em imagens mentais.

A memória, então, não é nem sensação nem julgamento, mas é um estado ou qualidade (afeição, afeto) de um deles, quando o tempo já passou. ... Toda memória, então, implica a passagem do tempo. Portanto só as criaturas vivas que são conscientes do tempo podem lembrar, e elas fazem isso com aqulea parte que é consciente do tempo. (Aristóteles, 1986, p. 291)

É obvio, então, que a memória pertence àquela parte da alma à qual a imaginação também pertence. Todas as coisas que são imagináveis são essencialmente objetos da memória, e aquelas que necessariamente envolvem a imaginação são objetos da memória apenas incidentalmente. A pergunta que pode ser feita é: como se pode lembrar alguma coisa que não está presente, se é apenas o afeto (sensação) que está presente, e não o fato? Porque é óbvio que se deve considerar o afeto que é produzido na alma pela sensação, e naquela parte do corpo que contém a alma (o afeto, o estado duradouro o qual chamamos memória) como um tipo de figura/retrato; porque o estímulo produzido imprime uma espécie de semelhança do percepto...

Falta ainda falar da recordação... ela não é nem a recuperação nem a aquisição da memória; porque quando se aprende ou recebe uma impressão sensória, não se recupera qualquer memória (porque nenhuma aconteceu antes), nem se adquire pela primeira vez; é somente quando o estado ou afeto foi induzido que existe memória... (Aristóteles 1986, p. 293)

Podemos destacar, então, três elementos ou aspectos que se tornam particularmente relevantes nas considerações de Aristóteles sobre a memória: as sensações e o afeto, a imaginação, e o tempo.

Além disso, com Aristóteles, a mímesis adquire novo estatuto: é imitação da natureza; representação; forma de conhecimento. A poesia é recuperada: como imitação e prazer; como catarse e purgação das emoções; como techné (arte). A poesia pode instruir e divertir.

Não é ofício do poeta narrar o que aconteceu; é, sim, o de representar o que poderia acontecer... Não diferem o historiador e o poeta por escreverem verso ou prosa... diferem, sim, em 
que um diz as coisas que sucederam, e o outro, as que poderiam suceder... (Poética, IX, 50)

\section{V.}

Essa citação de Aristóteles nos remete a considerações importantes sobre os primórdios do que chamamos história. Nos textos gregos a palavra história não existe. A palavra grega remete a histor - "aquele que viu". Trata-se de uma narrativa, de um relato informativo. Heródoto narra o que viu ou o que ouviu dizer. Há uma oposição crescente à narrativa mítica. História é testemunho. Distingue-se da epopéia homérica.

Imbricação e separação da palavra mítica e do discurso racional emergente:

'Heródoto de Halicarnassus apresenta aqui os resultados da sua investigação, para que a memória dos acontecimentos não se apague entre os homens com o passar do tempo, e para que os efeitos admiráveis dos helenos e dos bárbaros não caiam no esquecimento...'

Heródoto retoma e transforma a tarefa do poeta arcaico: contar os acontecimentos passados, conservar a memória, resgatar o passado, lutar contra o esquecimento. (Gagnebin 1997, p.17)

Heródoto não canta mais. Ele não é inspirado pelas Musas, para falar de um tempo longínquo, dos deuses e heróis, para falar das origens. Ele procura a causa dos acontecimentos. Ele fala de um tempo dos homens, de testemunhas. Mas ele não usa documentos escritos. Ele narra - primazia da oralidade - para informar e ensinar, mas também, pelo simples prazer de contar.

Ao ouvir Heródoto, Tucídides chora. Por que chora?... Ninguém o sabe.

Seguindo o mestre e se opondo a ele, Tucídides ressalta uma impossibilidade essencial: não se pode acreditar na memória para garantir a fidelidade do relato à realidade. Em oposição à toda tradição anterior, a memória em Tucídides não assegura nenhuma autenticidade. A memória é frágil, enganadora. Ela seleciona, interpreta, reconstrói: 
As testemunhas de cada fato apresentam versões que variam segundo sua simpatia com relação a um ou outro lado e segundo sua memória. (Tucídides, I, 22, 3, apud Detienne 1998, p. 105)

Segundo Gagnebin (1997), a desconfiança de Tucídides em relação à memória inscreve-se num projeto muito mais amplo, que chamaríamos, hoje, de crítica ideológica, pois memória e tradição formam este conglomerado confuso de falsas evidências, do qual o presente tira sua justificativa.

\begin{abstract}
A busca das verdadeiras razões dos acontecimentos através do testemunho próprio ou alheio inscreve-se neste esforço racional - do logos em oposição ao mythos - de escrita da nossa história. (Gagnebin, ibid. p. 20)
\end{abstract}

O fato é que, com Tucídides, registra-se uma ruptura radical: operando ainda sobre a tradição oral, sem arquivos e com raros documentos epigráficos, ele rompe com as "velhas histórias" de origem e natureza mítica, faz pouco caso do passado e da tradição. Há uma fissura entre Heródoto e Tucídides. Com a Guerra do Peloponeso, Tucidides trabalha na arquitetura austera e argumentativa do texto escrito para ser lido no futuro. Reivindica a escrita como meio de fixação dos acontecimentos, fazendo da imutabilidade do escrito uma garantia de fidelidade (bem ao contrário de Platão). Inaugura, assim, uma política da memória, e delimita os domínios de um novo saber histórico (Detienne 1998; Gagnebin 1997).

Oratória, retórica, escrita, história... Modos de trabalhar a memória. Ao par da arte e da técnica que se expandem, formas de controle, de poder. No "delírio da memória epigráfica" (Le Goff 1990), a possibilidade do confisco da memória coletiva, a tirania. Mas também, a damnatio memoriae, o apagamento, o desaparecimento, o esquecimento dos nomes dos imperadores nas inscrições monumentais. Destruição da memória.

V.

Principal responsável por trabalhar a arte da memória do grego para o latim, Cícero, no século I, seguindo a filosofia platônica, vai definir virtude como "hábito da mente em harmonia com a razão e a ordem da natureza" (apud Yates p. 20). Afirma que a virtude tem 4 partes: 
Prudencia, Justiça, Força e Temperança, as quais se subdividem em outras tantas partes. A memória é parte da prudência, junto com a inteligência e a providência. Yates comenta que "não temos como saber como 'coisas' como Prudência, Justiça, Força e Temperança e suas partes seriam representadas na memória artificial" e indaga: "Teria a Prudência, por exemplo, tomado uma forma mnemônica extremamente bela, uma persona, como alguém que a gente conhece...?" (1966 p. 21).

São essas as virtudes que se tornam cardinais na teologia cristã, e que são trabalhadas, nos séculos X e XI, por Santo Alberto e, sobretudo, por São Tomás na Suma Teológica. A memória é discutida por ele como parte da prudência e relacionada às regras da memória artificial. Com os trabalhos desses dois escolásticos, a concepção de memória vai se deslocando da retórica para a ética.

Foi o próprio Tomás de Aquino quem implantou solidamente a idéia de que os sistemas de memorização faziam parte da ética, sendo mais que meros componentes da retórica... Em seus comentários sobre Aristóteles, Aquino observou a importância das similaridades corpóreas - ou imagens da memória sob forma física - para impedir que coisas sutis e espirituais escapassem da alma... reforçava seus argumentos a favor do uso de sistemas de lugares-namemória... (Spence 1986, p.31)

A partir de locais e imagens, São Tomás formula três regras mnemônicas: 1. a memória está ligada ao corpo (sensações, imagens); 2. a memória é razão (ordenação, lógica); e 3. a memória é hábito de recordar (meditação preserva a memória).

Na Idade Média, teorias da memória desenvolveram-se, assim, na retórica e na teologia, retomando as idéias de loci e imagines, de Simônides. No século IV, Santo Agostinho já explorara, de maneira intensa e singular, a dimensão psicológica da memória, dando a estes locais e imagens dinamicidade, profundidade e fluidez:

Transporei, então, esta força da minha natureza, subindo por degraus até Àquele que me criou. Chego aos campos e vastos palácios da memória onde estão tesouros de inumeráveis imagens trazidas por percepções de toda espécie. $(\mathrm{X}, 8.12)$ 
Estes conhecimentos estão retirados num lugar mais íntimo que não é lugar. $(X, 9.16)$

E o que agora entendo e distingo, conservo-o na memória para depois me lembrar de que agora o entendi. Por isso lembro-me de que me lembrei. (X, 13.20)

Que é esquecimento senão a privação da memória? E como é, então, que o esquecimento pode ser objeto da memória se, quando está presente, não me posso recordar? Se nós retemos na memória aquilo de que nos lembramos, e se nos é impossível, ao ouvir a palavra 'esquecimento', compreender o que ela significa, a não ser que dele nos lembremos, conclui-se que a memória retém o esquecimento. A presença do esquecimento faz com que o não esqueçamos; mas quando está presente, esquecemo-nos. (X, 16.24)

Eis-me nos campos da minha memória, nos seus antros e cavernas sem número, repletas, ao infinito, de toda a espécie de coisas que lá estão gravadas, ou por imagens, como os corpos, ou por si mesmas, como as ciências e as artes, ou, então, por não sei que noções e sinais, como os movimentos da alma, os quais, ainda quando a não agitam, se enraízam na memória. (X, 17.26)

A ênfase de Agostinho é na memória como atividade psíquica. Ele se indaga sobre os vestígios que as imagens deixam na alma. Explicita as bases da introspecção, do exame de consciência. Faz uma versão da trilogia de Cícero, propondo a tríade: memória, vontade e inteligência.

$\mathrm{Na}$ trama de todas essas idéias, trabalhadas nas heranças e nas possibilidades de muitas interpretações, vai se fortalecendo uma tradição mnemônica cristã, que se centrava nas artes da memória como meio de ordenar as "intenções espirituais". Os sistemas de memorização são utilizados para lembrar o céu e o inferno. Surge a idéia de purgatório, a liturgia, o memento dos mortos. Esses modos de lembrar, essas idéias, esses locais e imagens, repercutem, por exemplo, na iconografia das pinturas de Giotto (imagens pintadas da Caridade, da Inveja, por exemplo), na estrutura e detalhes do Inferno de Dante, tornando-se lugar comum em muitos livros publicados no século XVI. Data desse século, justamente, o trabalho de Matteo Ricci, jesuíta que viveu na Índia e na China e desenvolveu na sua prática de catequese uma admirável arte da memória. Ricci constrói um Palácio da Memória, articulando o conhecimento da doutrina cristã com a cultura, e particularmente, com os ideogramas chineses (Spence 1986). 
Esses sistemas que tinham por base as imagens e o exercício da imaginação pela ordenação oralizada/mentalizada, desenvolve-se, nessa época, junto com, entrelaçados às práticas da escrita em difusão: leituras de textos sagrados, regras, memoriais, vão sustentando certos modos de lembrar, vão constituindo modos de pensar, vão compondo uma memória de caráter religioso, instrucional: é necessário aprender, repetir, recitar, de cor. Agora, com o apoio da escrita.

Ao par de cristianização da memória, em que a religião, o culto, o ritual, a celebração, a comemoração e o ensino se destacam, um movimento significativo merece ser mencionado nas elaborações e concepções sobre a memória, que diz respeito a uma interpretação cabalística, astrológica e mágica da memória. Giordano Bruno foi o maior teórico das teorias ocultistas da memória (Yates 1966; Le Goff 1986).

VII.

Em seu texto Memória e História, Le Goff (1986) apresenta uma abrangente e interessante síntese dos muitos aspectos, momentos, condições que envolvem a construção de, e a teorização sobre, a memória, nas suas relações com a história: memória individual/coletiva; memória como narrativa, identidade; memória como conteúdo psíquico; memória social, memória étnica; funções da oralidade e da escrita na construção da memória... Le Goff nos lembra dos homens-memória nas sociedades ágrafas; dos funcionários da memória, os mnemom (arquivistas), fazendo-nos lembrar, por exemplo, de Farenheit 451, ficção/filme que problematiza a função dos livros na sociedade e os modos de construção de um legado cultural no âmago das relações de poder.

O que persiste das idéias dos muitos autores, das muitas vozes, no nosso modo de pensar, conceber, e estudar a memória, no nosso discurso sobre memória hoje? O que persiste enquanto conhecimento, enquanto prática, enquanto arte da memória? Resquícios, vestígios, marcas...

Palavra (en)cantada, poesia. Oratória, retórica, exercícios para aprender. Locais e imagens. Imagines agentes. Pintura, iconografia. Palavra escrita. Logoi in biblíois. Livros, imprensa. Documentos. Monumentos. Fotos. Filmes. Vídeos. Computadores. Formas de narrar. Modos de lembrar. Memória natural, memória artificial. Memória para coisas, memória para palavras. Me- 
mórias da memória em funcionamento, constituindo-se no próprio processo de sua construção. Invenção da memória. Tradição. História.

Yates (1966) comenta sobre a longa agonia da arte da memória no século XVIII. Leroi-Gourhan (1964) vai falar sobre a memória em expansão, sobre as condições de externalização da memória, no sentido da criação de novos instrumentos, novas técnicas auxiliares, sobretudo a escrita e a imprensa: "Assiste-se, então, à exteriorização progressiva da memória individual; é do exterior que se faz o trabalho de orientação que está escrito no escrito" (1964, pp. 69-70).

Mas se as condições de externalização da memória vão se impondo no próprio processo de produção, nas próprias práticas, os estudos da memória individual também vão sendo fortemente privilegiados. Compreender os processos, examinar o funcionamento interno, orgânico, psíquico, vai se tornando uma demanda dentro de novas condições de possibilidade. Desdobram-se os modelos explicativos da memória e do processamento mental. A ênfase, agora, não está nos "locais e imagens da memória", mas na busca da memória "localizada" no cérebro, memória como um lugar, como sede, como órgão, foco das pesquisas nas ciências biológicas, médicas, cognitivas.

Com Bergson, assim como já com Santo Agostinho, cada um a seu modo, refletimos sobre a experiência subjetiva do tempo, a duração, a consciência. Com Freud, assim como com Aristóteles, examinamos os afetos nas lembranças. Com Freud, ainda, procuramos compreender as falhas na linguagem... falhas na memória? os esquecimentos...

O mnemonista de Luria apresentava, naturalmente, algumas características importantes da mnemotécnica. Locais e imagens eram vívidos, impactantes, persistentes. Aquilo que era, ou que podia ser proposto como exercício, como prática, como techné, como esforço de elaboração, como possibilidade de construção para a maioria das pessoas, era contingência biológica para ele, da qual não conseguia se descolar. As impressões sinestésicas eram agudizadas, os detalhes visuais intensos, a retenção inescapável... Ao par de uma memória figurativa excepcional de característica inata, havia uma impossibilidade de esquecer. A persistência da memória icônica atrapalhava, ou amarrava, a construção de sentidos, a compreensão de metáforas. Significar, interpretar, era extremamente penoso, dificultado. Se as imagens ficavam coladas à realidade, como trabalhar com idéias abstratas, que não se pode visualizar? "Só posso entender o que posso visualizar" (Luria 1968, p. 100). E Luria se indaga: 
Que efeito uma espantosa capacidade de memória tem em outros aspectos da personalidade, nos hábitos de pensamento e imaginação de um indivíduo, em seu comportamento e desenvolvimento da personalidade? Que mudanças ocorrem no mundo interno da pessoa, nas suas relações com os outros, no seu estilo de vida, quando um elemento do seu psiquismo - sua memória - desenvolve a um ponto tão incomum que começa a alterar cada um dos outros aspectos de sua atividade? (Luria, 1968, p. 13)

Uma capacidade fantasticamente desenvolvida, "fora da normalidade", tem o estatuto de patologia. Poderíamos estender essas reflexões às pessoas com deficiências visuais e/ou auditivas, e indagar sobre as noções de imagem que sustentam nossos modos de pensar. A imagem visual predomina e ganha lugar de destaque na construção da memória. Mas as imagens não se restringem às imagens visuais... São tantas as possibilidades de formação de imagens... táteis, sonoras... Como elas se tornam significativas? Entre o mnemonista de Luria, que não consegue esquecer, e os doentes de Alzheimer, que não conseguem lembrar, o que fica? O que significa? O que faz sentido?

VIII.

Vygotsky distingue entre imagens eidéticas e signos (1996), ressaltando a importância dos últimos na constituição da memória: "A verdadeira essência da memória humana está no fato de os seres humanos serem capazes de lembrar ativamente com a ajuda de signos" (Vygotsky 1989, p. 58). Lembrar com a ajuda de imagens, com a ajuda de signos. Memória artificial, memória mediada. Possibilidade de controle da memória nas formas de produção humana e nas estratégias de organização das imagens. Arte, Techné. Exercício da imaginação, constituição do imaginário.

A afirmação de Vygotsky, colocada em interlocução com tantos outros autores, nos leva a refletir sobre a força das imagens/signos na construção da memória. Leva-nos a pensar no que as imagens criadas pelos homens acabam por produzir, no que elas instauram, o que elas encobrem... Leva-nos a pensar no des-controle da memória, no esvaecimento das imagens, nos esquecimentos... E nos faz indagar sobre as formas de "comunicabilidade" e de sustentação das imagens nas relações com os signos, com as palavras. Problema archaico. 
Relembremos:

Precisamos, portanto, de locais, reais ou imaginários, e imagens ou simulacros que devem ser inventados. Imagens são como palavras pelas quais notamos o que aprendemos, de modo que, como Cícero dizia, usamos locais como cera e imagens como letras. (Quintiliano, apudYates, p. 22)

A alma nunca pensa sem uma imagem mental ... Vinda das impressões sensoriais, ela (a memória) não é específica do homem ... alguns animais também podem lembrar... No homem, o pensamento intervém nas imagens guardadas das impressões sensoriais. (Aristóteles, apud Yates, pp. 32-33)

Pensar é especular com imagens (Bruno, apud Yates, p. 289)

Os homens vão admirar os píncaros dos montes, as ondas alterosas do mar, as largas correntes dos rios, a amplidão do oceano, as órbitas dos astros: e nem pensam em si mesmos! Não se admiram de eu ter falado (agora) de todas estas coisas num tempo em que as não via com os olhos! Ora, não poderia falar delas se, dentro da minha memória, nos espaços tão vastos como se fora de mim os visse, não observasse os montes, as ondas, os rios, os astros que contemplei e 0 oceano em que acredito por testemunho alheio. (Agostinho, X, 8.15)

Dentre os grandes "pensadores da alma", Aristóteles e Agostinho exploraram a dimensão psíquica, discutiram profundamente as relações pensamento e linguagem, investiram na compreensão da memória e teorizaram sobre a função do signo na experiência humana.

Herdeiros da mesma tradição, e ancorados nas contribuições teóricas de tantos outros pensadores, Vygotsky e Bakhtin vão falar sobre a emergência e o funcionamento do signo na vida mental, a partir de uma perspectiva do materialismo histórico. O modo como interpretam o material semiótico no funcionamento mental nos sugere que a dimensão psicológica não pode ser separada da significação e do discurso. A realidade psicológica, de natureza fundamentalmente social, é necessariamente mediada/constituída por signos. A palavra, como signo por excelência, constitui modos específicos de ação significativa, de modo que a memória humana e a história tornam-se possíveis no/pelo discurso. Assim, onde existe imagem, imaginação, imaginário, memória, aí incide necessariamente o signo, e mais particularmente, a palavra - verbum. 
Ao ser capaz de imaginar o que não viu, ao poder conceber o que não experimentou pessoal e diretamente, baseando-se em relatos e descrições alheias, o homem não está encerrado no estreito círculo da sua própria experiência, mas pode ir muito além de seus limites apropriando-se, com base na imaginação, das experiências históricas e sociais alheias. (Vygotsky 1987, p. 21)

Estudar a memória no homem, então, não é estudar uma "função mnemônica" isolada, mas é estudar os meios, os modos, os recursos criados coletivamente no processo de produção e apropriação da cultura. Os trabalhos de Halbwachs, sociólogo francês, e de Bartlett, psicólogo inglês, contemporâneos de Vygotsky, Luria e Bakhtin, vão apontar, de maneiras diferenciadas, nessa mesma direção...

IX

Le Goff comenta sobre a "história que fermenta a partir do estudo dos "lugares" da memória coletiva" (1986, p. 473). E cita Pierre Nora:

Lugares topográficos como os arquivos, as bibliotecas, os museus; lugares monumentais como os cemitérios ou as arquiteturas, lugares simbólicos como as comemorações, as peregrinações, os aniversários ou os emblemas; lugares funcionais como os manuais, as autobiografias ou as associações: estes memoriais têm sua história. (ibid.)

Lugares de externalização da memória, a memória nas coisas, nas (manifest)ações coletivas. São muitos os sentidos de memória, muitos os sentidos de lugares da memória. Quando Le Goff e Nora mencionam os "lugares de memória" (topográficos, monumentais, etc.), estão se referindo a formas de "externalização" da memória, memória coletiva por excelência; quando Simônides, Agostinho e Ricci, por exemplo, falam de locais e imagens, de "lugares da memória", estão se referindo a locais mnemônicos, a possibilidades de organização e funcionamento mental, interno, memória individual; quando biólogos, médicos ou neurólogos mencionam os locais da memória hoje, podem indicar a busca da loca- 
lização cerebral desse funcionamento. Diante da impossibilidade de localizar os processos psíquicos, Freud, há quase um século, propõe um deslocamento:

A nossa tópica psíquica não tem nada a ver com a anatomia; não se refere a localidades anatômicas, mas a regiões do aparelho psíquico, prescindindo do lugar em que elas possam estar situadas (Freud apudVerdiglione 1977, p. 12).

Lembrar Agostinho:

Estes conhecimentos estão retirados num lugar mais íntimo que não é lugar. (X, 9.16)

Herdamos todas essas contribuições, todas essas discussões, todos esses sentidos de memória. E consideramos pertinente trazer ainda uma outra dimensão a ser explorada: o discurso como (locus de?) memória.

Estudos sobre memória têm nos mostrado que o discurso constitui lembranças e esquecimentos, que ele organiza e mesmo institui recordações, que ele se torna um locus da recordação partilhada - ao mesmo tempo para si e para o outro - locus portanto, das esferas pública e privada. Sob os mais diversos pontos de vista, a linguagem é vista como o processo mais fundamental na socialização da memória. A possibilidade de falar das experiências, de trabalhar as lembranças de uma forma discursiva, é também a possibilidade de dar às imagens e recordações embaçadas, confusas, dinâmicas, flúidas, fragmentadas, certa organização e estabilidade. Assim, a linguagem não é apenas instrumental na (re)construção das lembranças; ela é constitutiva da memória, em suas possibilidades e seus limites, em seus múltiplos sentidos, e é fundamental na construção da história.

Encontramos nos cantos homéricos, na pintura e na poesia de Simônides, nas imagens e nas palavras, na mnemotécnica, possibilidades de narrar, formas de sustentação da memória. Memória para coisas, memória para palavras. Desde os gregos, a questão persiste. Com Santo Agostinho, Santo Tomás, Freud, Luria, os psicólogos atuais... A pala- 
vra remete a imagens e a coisas. Mas a palavra também cria, constitui, institui relações e formas de ação. Aristóteles menciona que

\begin{abstract}
Assim como em uma pessoa com uma memória treinada, a memória das próprias coisas é imediatamente causada pela mera menção dos seus locais - topoi - assim também esses hábitos tornarão um homem mais preparado ou pronto para raciocinar, porque ele tem suas premissas classificadas nos olhos de sua mente, cada uma sob seu número. (Aristóteles, apud Yates, 1966, p. 31 , grifos nossos)
\end{abstract}

Ressaltar nessa citação a "mera menção dos topoi" é provocar uma reflexão sobre o estatuto da linguagem nos estudos da memória. Yates comenta:

\begin{abstract}
Não pode haver dúvida de que esses topoi usados por pessoas com uma memória treinada deve constituir locais - loci-mnemônicos e é ainda provável que a própria palavra "tópicos", usada na dialética, emergiu pelos locais da mnemônica. Tópicos são as coisas ou assuntos da dialética que passaram a ser conhecidos como topoi pelos lugares nos quais eram armazenados. (Yates, p. 31)
\end{abstract}

Recentemente, Ducrot retoma/introduz a noção de topos na sua Teoria da Argumentação na Língua (Banks-Leite, 1996). Um topos é algo comum, partilhado e aceito por uma comunidade (pode ser também reconhecido na fala de um outro (diferente) sem que haja partilha). Um "feixe de topoi" constitui o significado das palavras historicamente construído.

Os topoi aparecem como um lugar ao mesmo tempo de estabilização, de contenção, e de mobilização e produção de sentidos, indício de memória na língua, lugar comum... ao mesmo tempo, da ideologia e da subjetividade.

Bakhtin nos lembra que

a palavra é o fenômeno ideológico por excelência... é o modo mais puro e sensível de relação social $(1981$, p. 36) 
Nenhum signo cultural, quando compreendido e dotado de um sentido, permanece isolado: torna-se parte da unidade da consciência verbalmente constituída... A palavra está presente em todos os atos de compreensão e em todos os atos de interpretação (Bakhtin, 1981, p. 38)

Assim, aspectos do que conceituamos como "hitórico-cultural", "ideológico" podem se tornar visíveis em uma análise da materialidade da língua, que constitui e estabiliza modos de ação e de elaboração mental, como práticas inscritas e instituídas na cultura. Se de algum modo nos preocupamos em compreender como a palavra vai forjando e transformando a memória, ou seja, como a memória (dita) psicológica vai se constituindo e se organizando no e pelo discurso, podemos também problematizar como a memória vai se inscrevendo na palavra, como as práticas vão se inscrevendo no discurso, como aquilo que se tornou objeto da fala e da emoção humana perdura ou se esvai ... (Smolka 1997)

Encaminhado para publicação em maio de 2000

\section{Memory at issue: a historical-cultural perspective}

ABSTRACT: This article brings to the fore the issue of memory as social practice. It focuses on the many historically constituted ways of thinking and speaking about memory. It looks for the understanding of the collective modes of elaboration of memory, searching for signs or marks of this constitution at the level of the individual and inquiring about the discursive dimension and the status of language in this constitution.

\section{Bibliografia:}

ARISTÓTELES. Da memória e da reminiscência.

. On the soul - parva naturalia - on breath. Harvard University

Press, Cambridge, Mass.1986

BADDELEY, A. La Mémoire Humaine: Théorie et Pratique. Grenoble:PUG, 1993.

BANKS-LEITE, L. Aspectos argumentativos e polifônicos da linguagem da criança em idade pré-escolar. Tese de Doutorado. IEL/Unicamp, Campinas, 1996. 
BARTLETT, F. Remembering: a study in experimental and social psychology: London:Cambridge University Press, 1977. [Original de 1832]

BERGSON, H. Matéria e memória. São Paulo: Martins Fontes, 1990.

BOBBIO, N. O tempo da memória. De senectude e outros escritos autobiográficos. Rio de Janeiro: Campus, 1997.

BOSI, E. Memória e sociedade. Lembranças de velhos. São Paulo: Queiroz/ Edusp, 1987.

BRAGA, E. S. Aspectos da constituição social da memória no contexto pré-escolar. Dissertação de mestrado. Faculdade de educação, Unicamp, Campinas, 1995.

BRANDÃO, C. As faces da memória. Campinas:CMU, Coleção Seminários, 1995.

CONY, C.H. Quase memória: quase romance. São paulo: Companhia das Letras, 1995.

DERRIDA, J. A farmácia de Platão. São Paulo: lluminuras, 1991.

DETIENNE, M. Os mestres da verdade na Grécia Arcaica. Rio de Janeiro: Zahar, 1988.

A invenção da mitologia. Rio de Janeiro: José Olímpio; Brasília: UnB. $2^{a}$. edição, 1998.

EDWARDS, D., POTTER, J. \& MIDDLTON, D. "Toward a discursive psychology of remembering". The Psycholgist: Bulletin of the British Psychological Society, vol 5, 1992, pp. 441-446.

FELLINE, F. Je suis un grand menteur (Entretien avec Damien Pettigrew) Paris:L'arche, 1994.

FOUCAULT, M. A arqueologia do saber. Rio de Janeiro: Forense-Universitária, 1969.

FREUD, S. A interpretação das afasias. Lisboa, Edições 70, 1977. [Original de 1891]

Lembranças encobridoras. Rio de Janeiro: Imago, 1989. Obras Completas, vol. III. pp. 333-354. [Original de 1899]

. Sobre a psicopatologia da vida cotidiana. Rio de Janeiro, Imago, 1987. [Original de 1901] 
GAGNEBIN, J.M. Sete aulas sobre linguagem, memória e história. Rio de Janeiro: Imago, 1997.

HALBWACHS, M. A memória coletiva. São Paulo: Edições Vértice, 1990. [Original de 1968]

HAVELOCK, E. Prefácio a Platão. Campinas: Papirus, 1996. [Original de 1965] A revolução da escrita na Grécia e suas conseqüência culturais. São Paulo: Editora da Unesp/Paz e Terra, 1996. [Original de 1982]

HESÍODO. Teogonia - a origem dos deuses. Tradução comentada de Jaa Torrano, São Paulo, lluminuras, 1991.

LE GOFF, J. História e memória. Campinas: Editora da Unicamp, 1996, Capítulo sobre "Memória" (pp.423-484).

LEROI-GOURHAN, A. Le geste et la parole. Paris: Michel, 1994.

LURIA, A.R. The mind of a mnemonist. UK: Basic Books, 1968.

. Fundamentos de Neuropsicologia (tradução de The working brain - An introduction to Neuropsychology) [S.R], 1981.

MAINGUENEAU, D. Novas tendências em Análise do Discurso. Campinas: Editora da Unicamp/Pontes, 1989. [Original de 1987] . Génèses du discours. Paris: Mardaga, 1984.

MENEZES, A. Memória: matéria de mímese. In Brandão, C., As faces da memória. Campinas:CMU, Coleção Seminários, 1995.

MIDDLETON, D.; EDWARDS, D. Memoria Compartida. La naturaleza del recuerdo y del olvido. Barcelona: Paidós, 1990.

MORATO, E.M. Um estudo da confabulação no contexto neuropsicológico: $\mathrm{O}$ discurso à deriva ou as sem-razões do sentido. Tese de Doutoramento. IEL/UNICAMP, 1995.

PÊCHEUX, M. Análise Automática do Discurso. Por uma análise automática do discurso (Gadet, F. \& T. Hak, ogs.). Campinas: Editora da Unicamp, 1990. [Original de 1969]

. Semântica e Discurso: uma crítica à afirmação do óbvio. Campinas: Editora da Unicamp. pp.123-149, 1988. [Original de 1975]

PIRES, J.C. De profundis, valsa lenta. Rio de Janeiro: Bertrand Brasil, 1998.

PLATÃO. Fédon. (in Diálogos: Fédon - Sofista - Político). Ediouro, s/d. 
. Fedro, ou da Beleza. Lisboa: Guimarães, 1990.

PROUST, M. Em busca do tempo perdido. Rio de Janeiro: Globo, 1988.

ROSENFELD, I. L'invention de la mémoire. Paris, Flammarion, 1989.

SACKS, O (1988) O homem que confundiu sua mulher com um chapéu. Rio de Janeiro: Imago, 1988.

. Um antropólogo em Marte. São Paulo: Companhia das Letras, 1995.

SANTO AGOSTINHO. Confissões. In Os pensadores. São Paulo: Nova Cultural, 1984. Livro X 7-26 (sobre memória); Livro XI (sobre o homem e o tempo).

. De Magistro. In: Os pensadores. São Paulo: Nova Cultural, 1984.

SIGNORET, J.L. Les troubles de mémoire. Neuropsychologie clinique et Neurologie du comportement. Montréal. Les Presses de l'Université de Montréal, 1987.

Smolka, A. L. B. Linguagem e conhecimento na sala de aula: modos de inscrição das práticas cotidianas na memória coletiva e individual. Anais do Encontro sobre teoria e Pesquisa em Ensino de Ciências: linguagem, cultura e cognição. FE/UFMG/FE/UNICAMP. (pp.97-113), 1997.

SPENCE, J. O palácio da memória de Matteo Ricci. São Paulo: Companhia das Letras, 1986.

TRILLET, M. \& LAURENT, B. Mémoire et amnésies. Paris: Masson, 1988. (Cap. 1: Mémoire et oubli chez le sujet normal (pp.49-62),

TULVING, E. "Memory: Perfomance, knowledge and experience". European Journal of Cognitive Psychological, 1989, 1:3-26.

VAN DIJK, T. Cognição, Discurso e Interação. São Paulo: Contexto, 1992. [Original de 1988]

VIGNAUX, G. Les Sciences Cognitives - Une introduction. Paris:La DÉCOUVERTE, 1991. Capítulo 3 (pp.198-211).

VYGOTSKY, L.S. Lectures on Psychology. The collected works of L.S. Vygotsky. Vol.I. Problems of General Psychology. New York: Plenun Press, 1987. [Original de 1932]

A formação social da mente. São Paulo: Martins Fontes, 1984. [Original de 1929] 
. Estudos sobre a história do comportamento: o macaco, o primitivo e a criança. Porto Alegre: Artes Médicas, 1996. [Original de 1930]

. Imaginación y el arte en la Infancia. México: Hispánicas, 1987. [Original de 1930]

. "Concrete Human Psychology". Soviet Psychology. 27 (2), pp. 53-77. [Publicação original 1986; escrito em 1929]

YATES, F. A. The art of Memory: Chicago University Press, 1966.

YOURCENAR, M. Memórias de Adriano. Rio de Janeiro: Nova Fronteira, 1980. 